\title{
Spine surgery tricks of the trade
}

\author{
Editors: Alexander Vaccaro and Todd Albert Hardcover, \\ ISBN: 978-1-58890-519-2 Thieme
}

\author{
Michael Payer
}

Published online: 4 September 2009

(C) Springer-Verlag 2009

The book Spine Surgery-Tricks of the Trade by Alexander Vaccaro and Todd Albert, Second Edition, definitely holds true to its title. On a little over 300 pages of this hardcover book, over 80 authors, mainly from the USA but also from other countries, have put together a fascinating overview of modern spine surgery techniques. As stated in the title, this book is fostering on the technical aspects of spinal surgery and is not a text book about spinal disease.

The book is extremely well structured with systematic descriptions of posterior then anterior approaches, each first without instrumentation then with instrumentation, from the craniovertebral junction down to the sacrum. Special sections about deformity, minimally invasive procedures, bone grafting, external immobilization, motion-preserving procedures, and complication management follow to round up the spine surgeon's potential armamentarium. The last section "Complications Management" is particularly useful to busy spine surgeons as dealing with complications and awareness of their best management is often neglected in the current literature as complications are generally under-reported.

Each surgical procedure is described in the same systematic manner with the subheadings: "Description",

M. Payer $(\bowtie)$

Klinik Hirslanden Zürich and University of Geneva,

Mockenwiesstrasse 37d,

8713 Uerikon, Switzerland

e-mail: mpayer@hotmail.com
"Key principles", "Indications", "Contraindications", "Special Considerations", "Special instructions/position/ anesthesia", "Tips/pearls and lessons learned", "Difficulties encountered", "Key procedural steps", "Bailout/ rescue/salvage procedures", and "Pitfalls". The letter size is somewhat small and needs careful reading but seems necessary to confine text length to about 3-5 pages per technique on average, which maintains excellent overview. Furthermore, this book is probably not designed for systematic read-through but rather for a pinpointed workup or brush-up of one or more specific procedures. Again, the clear structure here makes it a pleasure to find and read through the chapter(s) needed. The illustrations fit well into the chapter, and though only black and white, they are clear and instructive. The index is helpful and clear. There are no references; rather, the authors of each procedure chapter are listed directly below the title of the chapter.

As spinal surgery has impressively evolved over the past two decades, it is of paramount importance not to lose the overview of available surgical solutions and to know their pros and cons. This is exactly what this book offers: only very little (and understandable!) bias is noted in the technical descriptions by the authors. Rather, a useful selfcritical style has been implicated by such subheadings as "Difficulties encountered", "Bailout/rescue/salvage procedures", and "Pitfalls". Such a differentiated presentation of strengths and weaknesses of procedures will allow the neurosurgical or orthopedic resident, spine fellow, or fully trained specialist to make his or her own and best therapeutic choice in a given situation. 